\title{
Effect of Plasma Cladding Speed on the Microstructure and Properties of $\mathrm{ZrC}-\mathrm{ZrB}_{2} / \mathrm{NiAl}$ Coating
}

\author{
Pengcheng Xia ${ }^{a, *}$ (D), Ye Li ${ }^{a}$, Kun Xie ${ }^{a}$, Meiqing Cao ${ }^{a}$, Yunliang Tan \\ ${ }^{a}$ Shandong University of Science and Technology, School of Material Science and Engineering, 266590, \\ Qingdao, China \\ ${ }^{b}$ Shandong University of Science and Technology, Shandong Province and the Ministry of Science and \\ Technology, State Key Laboratory of Mining Disaster Prevention and Control Co-founded, 266590, \\ Qingdao, China
}

Received: November 23, 2020; Revised: March 26, 2021; Accepted: April 27, 2021

\begin{abstract}
$\mathrm{NiAl}$ composite coating strengthened by $\mathrm{ZrC}$ and $\mathrm{ZrB}_{2}$ phases is synthesized by the plasma cladding process. The influence of cladding speed on microstructrue and properties of coatings is studied. The main phases of coatings are $\mathrm{NiAl}, \gamma$ - $(\mathrm{Fe}, \mathrm{Ni}), \mathrm{ZrC}$ and $\mathrm{ZrB}$, phases. $\mathrm{ZrC}$ is in the shape of points and small blocks, $\mathrm{ZrB}_{2}$ shows long strips and needle bar. The slower the cladding speed, the larger the size of the reinforcing phases. With the increase of cladding speed, the wear resistance of the coatings improves. Coating with the cladding speed of $10 \mathrm{~mm} / \mathrm{s}$ has excellent wear-resistance property owing to high hardness and low friction coefficient. $\mathrm{ZrC}$ and $\mathrm{ZrB}_{2}$ strengthening phases play an important role. The main wear mechanism of NiAl composite coating is adhesive wear.
\end{abstract}

Keywords: $\mathrm{ZrC}$-ZrB_/NiAl composite coating, in-situ synthesis, wear resistance, microhardness

\section{Introduction}

Wear caused by mechanical friction is the interaction between parts and other components. The wear failure makes great economic loss ${ }^{1}$. Indirect losses caused by fracture and abrasion are more difficult to statistics. It is necessary to explore wear resistant of coating to improve the surface properties of metal materials.

Metal-matrix composite (MMC) coatings have excellent properties, such as specific stiffness, good thermal conductivity and good corrosion resistance, high modulus, stability at high temperature and wear resistance ${ }^{2-4}$. They are comprehensive applied as promising candidates of advanced materials.

The NiAl intermetallic compound which has low density, high melting point, good corrosion resistance, good oxidation resistance and heat conduction performance is widely used as high temperature structure material and coating material ${ }^{5-7}$. However, the low strength and plasticity at high temperature confine its application ${ }^{8-10}$.

The ceramic phase has the advantages of high strength and high hardness. $\mathrm{ZrC}$ and $\mathrm{ZrB}$, phases have a series of advantages such as high melting point and hardness, high temperature stability, strong wear resistance ${ }^{11,12}$. There are many literatures about the composites or coatings which are strengthened by $\mathrm{ZrC}$ or $\mathrm{ZrB}_{2}$ phases ${ }^{13-17}$. Those materials have good properties such as wear resistance ${ }^{13,16}$, ablation resistance ${ }^{15}$, oxidation resistance ${ }^{17}$, and so on. It is anticipated that the $\mathrm{ZrC}-\mathrm{ZrB}_{2} / \mathrm{NiAl}$ composite coating with excellent corrosion resistance and wear resistance can act as a candidate coating materials in many fields.

Plasma cladding process is widely used to many industrial aspects because of high heating, good controllability and low

*email: xpc328@126.com $\operatorname{cost}^{4,18,19}$. At present, there are relatively few studies on the effect of scanning speed on the properties and microstructure of coatings by plasma cladding. In this work, the $\mathrm{ZrC}-\mathrm{ZrB}_{2} /$ $\mathrm{NiAl}$ coating is fabricated by plasma cladding process. The influence of plasma cladding speed on the properties and microstructure is investigated. It is of great significance to optimize the technological parameters of plasma cladding and improve the properties of coating.

\section{Experimental Procedures}

The raw materials are commercially available $\mathrm{Ni}$ powder(purity 99.5\%), Al powder(purity 99\%), B $\mathrm{C}$ (purity $97 \%$ ) and $\mathrm{Zr}$ (purity 99\%), which are used to prepared the $\mathrm{NiAl}$ composite coatings. The matrix of composite coating is $\mathrm{Ni}$ and $\mathrm{Al}$ with the atomic ratio of $1: 1$. The $\mathrm{ZrC}$ and $\mathrm{ZrB}_{2}$ phases are created by the reactions of $3 \mathrm{Zr}+\mathrm{B}_{4} \mathrm{C} \rightarrow \mathrm{ZrC}+2 \mathrm{ZrB}_{2}$. The mass percent of $\mathrm{ZrC}-\mathrm{ZrB}$, strengthening phases is $30 \%$ in the coating. Alloy powders are mixed uniformly in a three-dimension blender for six hours. The total mass of coating powders is 10 grams. The mass of $\mathrm{Ni}, \mathrm{Al}, \mathrm{Zr}$ and $\mathrm{B}_{4} \mathrm{C}$ is differently about 4.8 grams, 2.2 grams, 2.5 grams and 0.5 grams. The average size of mixed powders is about $75-110 \mu \mathrm{m}$. Substrate material used in this experimental is Q235 low carbon steel which has the size of $120 \mathrm{~mm} \times 50 \mathrm{~mm} \times 5 \mathrm{~mm}$. The nominal chemical composition is (wt. \%): C $0.15, \mathrm{Mn}$ 0.45 , Si 0.3 , bal. Fe. The mixed homogenous powder is pressed on the surface of Q235 with sodium silicate solution (as binder) and the thickness of pre-coating is about $1 \mathrm{~mm}$ with the scan cladding speeds of $8 \mathrm{~mm} / \mathrm{s}$ (coating 1 ), $9 \mathrm{~mm} / \mathrm{s}$ (coating 2), 10mm/s (coating 3), respectively. The $\mathrm{NiAl}$ composite coatings are produced by plasma cladding process. 
The process parameters of plasma cladding are listed in Table 1. The metallo-graphic sample is cut along the crosssection of the coated samples. The microstructure is observed by Nikon ME600 optical microscope. The composition is analyzed by JXA-8230 electron probe microanalysis (EPMA). The phase of the prepared composite coating is identified by $\mathrm{X}$-ray diffraction (XRD) with $\mathrm{Cu} \mathrm{K} \alpha$ radiation. Vickers microhardness testing is carried out with a load of $50 \mathrm{~g}$ in 15 seconds on FM-700/SVDM4R Automatic micohardness tester. The tribological tests of the coats are performed by using CETR-UMT-3MO multifunctional friction and wear testing machine with a GCr15 friction wheel (hardness HRC63) and a load of $50 \mathrm{~N}$ under dry sliding conditions. The wear volume of the coating is measured by a 3D topography instrument.

\section{Results and Discussion}

\subsection{Microstructure of coatings}

Figure 1 shows the EPMA micrographs of Ni, Al, Zr and $\mathrm{B}_{4} \mathrm{C}$ raw powders. The $\mathrm{Ni}$ and $\mathrm{Al}$ powders present spherical shapes and the size is the range of $45-75 \mu \mathrm{m}$. The $\mathrm{Zr}$ and $\mathrm{B}_{4} \mathrm{C}$ powders present cuttings shape and granular, the size is about $20-75 \mu \mathrm{m}$. All of the powders are mixed uniformly and make sure the good flowability and full reaction.

Figure 2 demonstrates the XRD patterns of coatings obtained by different cladding speed. The original powders are not detected in $\mathrm{XRD}$, which indicates that the reaction has been fully carried out as expected. It can be seen from Figure 2 that microstructure of $\mathrm{NiAl}$ composite coatings is mainly composed of $\mathrm{NiAl}, \gamma-(\mathrm{Fe}, \mathrm{Ni}), \mathrm{ZrB}_{2}$ and $\mathrm{ZrC}$ phases.

Table 1. Parameters of plasma cladding.

\begin{tabular}{cc}
\hline Current $(\mathrm{A})$ & 90 \\
\hline Voltage $(\mathrm{V})$ & 30 \\
\hline Scanning velocity $(\mathrm{mm} / \mathrm{min})$ & 600 \\
\hline Plasma gas flow $\left(\mathrm{Ar}, \mathrm{m}^{3} / \mathrm{h}\right)$ & 0.2 \\
\hline Protective gas flow $\left(\mathrm{Ar}, \mathrm{m}^{3} / \mathrm{h}\right)$ & 0.5 \\
\hline
\end{tabular}
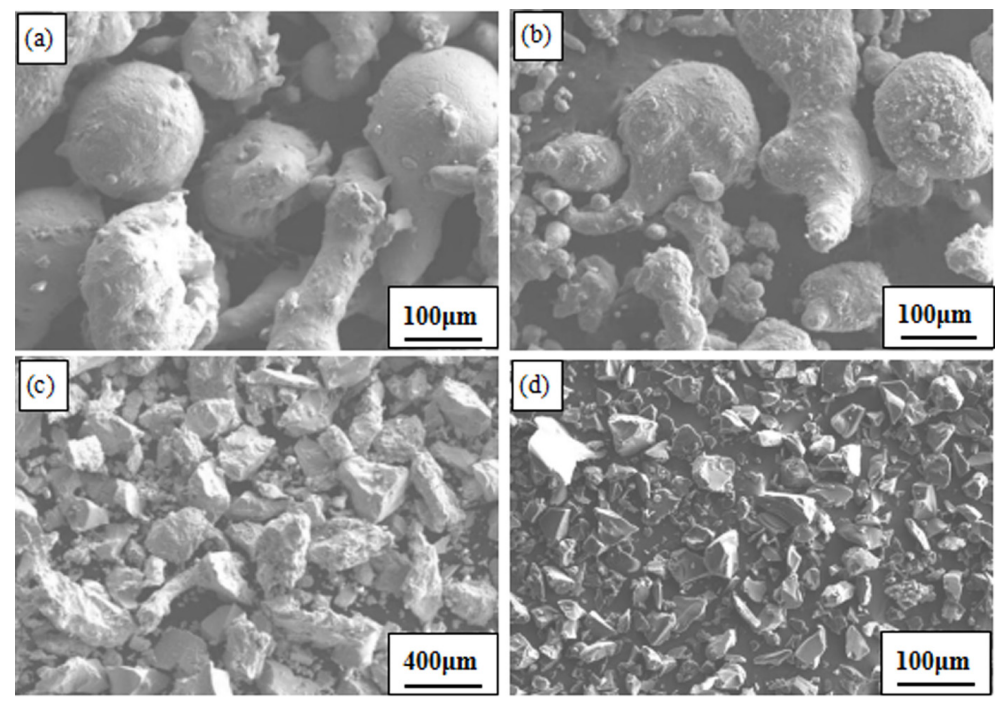

Figure 1. EPMA micrographs of raw powders of (a)Ni (b)Al (c) $\mathrm{Zr}(\mathrm{d}) \mathrm{B}_{4} \mathrm{C}$.

The surface of Q235 and raw powders are melted and a molten pool is formed during the plasma cladding process. The diffusion of elements such as $\mathrm{Fe}, \mathrm{Ni}$ and $\mathrm{Al}$ atoms will generate at the interface of the substrate and the coating. $\mathrm{Fe}$ atoms diffuse from the substrate to the coating and solute into $\mathrm{Ni}$ atoms. They form $\gamma$-(Fe, Ni) solid solution. The diffusion is discussed later at the end of section 3.1.

Figure 3 shows that cross-sectional micrograph of coating 2. The coating is compact and uniform. The transition zone from coating to substrate is continuous. The interface between coating and substrate is free obvious porosities and cracks. It indicates that the coating has good formability and forms metallurgical bonding with the Q235 steel.

It can be seen the shape and size of strengthening phase in Figure 4. The size of long bar reinforcement is about $3-5 \mu \mathrm{m}$ when the cladding speed is small (Figure $4 \mathrm{a}$ ). The bar strengthening phase becomes fine with the rise of cladding speed (Figure $4 b, c)$. The size of bar reinforcing phase is about $1-2 \mu \mathrm{m}$ when the cladding speed is $100 \mathrm{~mm} / \mathrm{s}$ (Figure $4 \mathrm{c}$ ). There are two different shape phases. The one has the shape of needle or long bar and the other one is petals and small block shape. The main elements of long bar or needle phase is $\mathrm{Zr}$ and $\mathrm{B}$ in Figure $4 \mathrm{e}$ according to $\mathrm{B}$ point in Figure $4 \mathrm{c}$. It is $\mathrm{ZrB}_{2}$ phase. The energy spectrum analysis of small block or petals phase is shown in Figure $4 \mathrm{f}$ according to the $\mathrm{C}$ point in Figure $4 c$, which contains $\mathrm{Zr}$ and $\mathrm{C}$ elements. It is $\mathrm{ZrC}$ phase. The main elements of the matrix are $\mathrm{Ni}, \mathrm{Al}$ and $\mathrm{Fe}$ (Figure $4 d$ according to the A point in Figure 4c). The main phases of coating matrix are $\mathrm{NiAl}$ and $\gamma-(\mathrm{Fe}, \mathrm{Ni})$. During plasma cadding Fe diffusses from Q235 steel to coatings resulting in the formation $(\mathrm{Fe}, \mathrm{Ni})$ phase $^{18}$.

The width of $\mathrm{ZrB}_{2}$ gradually reduces with the raising cladding speed (Figure 4a-c). The coating and substrate are melted and form molten pool by the plasma heating. The volume of melted pool is large for gaining more energy when the cladding speed is small. The solidification time is prolonged. The strengthening phase has more time to grow. So the size of $\mathrm{ZrB}_{2}$ in the coating 1 is larger than that in coating 2 and coating 3 (Figure 4). 


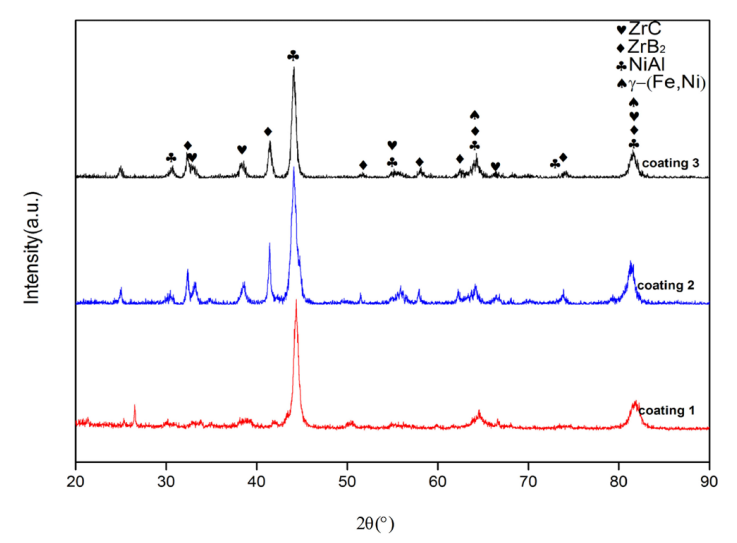

Figure 2. XRD patterns of the NiAl composite coatings.

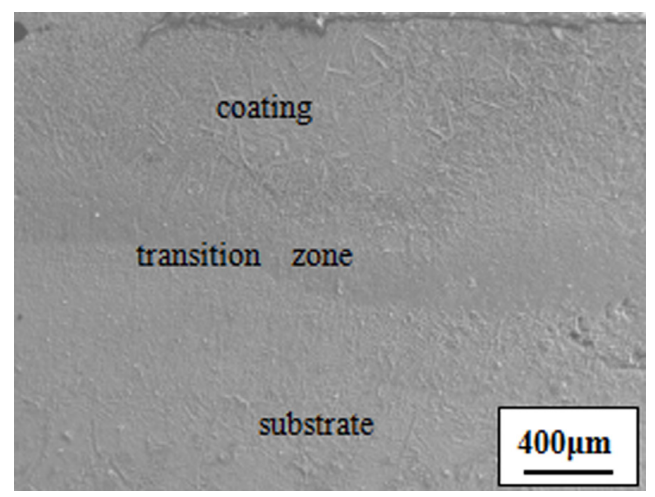

Figure 3. Cross-sectional micrograph of coating 2.

Surface scan map of coating 1 is shown in Figure 5, which can further illustrate the corresponding relationship between the strengthening phase and the element distribution. Figure 5a shows the microstructure of coating 1 . It demonstrates the needle bar shape and small block grains clearly. Figure $5 \mathrm{~b}$ shows that $\mathrm{C}$ element is mainly distributed in block or petals phase. Figure $5 \mathrm{c}$ and $\mathrm{d}$ show the distribution of $\mathrm{B}$ and $\mathrm{Zr}$ elements respectively. These elements are mainly distributed in the bright grey needle bar-like area. It can be deduced that the bright grey particles with needle or long bar shapes are $\mathrm{ZrB}_{2}$ and the small block particles around the needle bar are $\mathrm{ZrC}$. Figure 5e and f show that $\mathrm{Ni}$ and $\mathrm{Al}$ elements. They are mainly distributed in the area outside the needle bar. Two elements are always distributed in the same area. The main phases outside the needle or bar phase region are $\mathrm{NiAl}$.

The reaction between raw powders is induced by the massive heat released by plasma cladding process. The Al and $\mathrm{Ni}$ powders first melt for low melting points. NiAl phase is fabricated by the reaction of $\mathrm{Al}$ and $\mathrm{Ni}$. Then $\mathrm{Zr}$ powder starts to melt for lower melting point $\left(1852^{\circ} \mathrm{C}\right)$ than that of $\mathrm{B}_{4} \mathrm{C}\left(2350^{\circ} \mathrm{C}\right)$ by plasma cladding process. Liquid $\mathrm{Zr}$ clads $\mathrm{B}_{4} \mathrm{C}$. The molten $\mathrm{Zr}$ reactes and forms $\mathrm{ZrB}_{2}$ and $\mathrm{ZrC}$ with $\mathrm{B}_{4} \mathrm{C}$ through a liquid-solid diffusion. The $\mathrm{B}_{4} \mathrm{C}$ is decomposed into $4[\mathrm{~B}]$ and $[\mathrm{C}]$ in high temperature molten pool by plasma heating further. There exist more $[\mathrm{B}]$ than [C] in molten pool. The liquid phase will be beneficial to the reaction of $\mathrm{Zr}$ and $\mathrm{B}_{4} \mathrm{C}$. The $\mathrm{ZrC}$ is first nucleated for higher melting point $\left(3540^{\circ} \mathrm{C}\right)$ than that of $\mathrm{ZrB}_{2}\left(3250^{\circ} \mathrm{C}\right)$.
Subsequent, $\mathrm{ZrB}_{2}$ nucleates. $\mathrm{ZrB}_{2}$ has hexagonal structure. The favorable growth direction is [0001]. The growth speed of [0001] direction is rapid. The $\mathrm{ZrB}_{2}$ has the morphology of needle or stick shape. $\mathrm{ZrC}$ has face centered cubic structure. The growth speeds of every direction is near equal. $\mathrm{ZrC}$ has the block shape.

Figure 6 shows the element line scan of the coating 3 . $\mathrm{A}, \mathrm{B}$ and $\mathrm{C}$ points represent the surface of the coating, the interface and the substrate respectively. It shows that $\mathrm{Fe}$ element gradually reduces from substrate to the coating. $\mathrm{Al}$ and Ni elements gradually increase from substrate to the coating. There are no abrupt element fluctuations, which indicates that the coating has formed a good metallurgical combination with the substrate.

\subsection{Coating properties}

The microhardness curves of coatings from surface to substrate are shown in Figure 7. The hardness of the coating gradually increases with the rising distance from coatings surface and it reaches the highest ( about HV780 of coating 3 ). Then it starts to decrease and finally the hardness is stable in the substrate (about HV180). The hardness of the coatings surface is not the highest. The pre-coating and partial substrate are melted and form molten pool by plasma arc heating. The metal begins to solidify when the plasma arc leaves. The coating near substrate first crystals by substrate chilling. The coating surface finally solidified. There are a small amount of porosities and defects on the coating surface. Due to the high temperature of plasma arc, the elements of $\mathrm{Ni}, \mathrm{Al}$ and $\mathrm{Zr}$ on the surface of coatings seriously are burned loss. In addition, the bottom of coating has large cooling rate and high temperature gradient because the heat is absorbed by substrate. The temperature of the substrate rises rapidly due to absorption of heat. The cooling rate of the molten pool reduces and the temperature gradient lows when the surface alloy of coating solidifies. There is large supercooling area. The strengthening phases have enough time to nucleate and grow. The size of the reinforcing phases are relatively larger in the surface of coating. The smaller size of the strengthening phases, the better strengthening effect on the coating. All of these reasons cause lower hardness on the surface of coating.

The hardness is the highest at $250-450 \mu \mathrm{m}$ from the surface of the coating. The density of B element and C element are low, which are easy to gather at the surface of the molten pool. There is more reinforcing phases than that in bottom. Therefore, the hardness of the coating is higher than the bottom of the coating.

The hardness curve of the coating is not consistent by different cladding speed. It is related with the size of strengthening phases and surface formability. The hardness of coating 3 is the highest. The mean hardness of coating 3 (about $700 \mathrm{HV}$ ) is more than three times that of the substrate (about $180 \mathrm{HV}$ ). The coating 3 contains a large amount of $\mathrm{ZrC}$ and $\mathrm{ZrB}_{2}$ reinforcing phases. When the coatings are subjected to external pressure, the strengthening phases increase the resistance to dislocation movement. The hardness and strength of reinforcing phases are much higher than that of the Q235 substrate. The cladding speed of coating 3 is $10 \mathrm{~mm} / \mathrm{s}$. The temperature of molten pool is lower than that of 

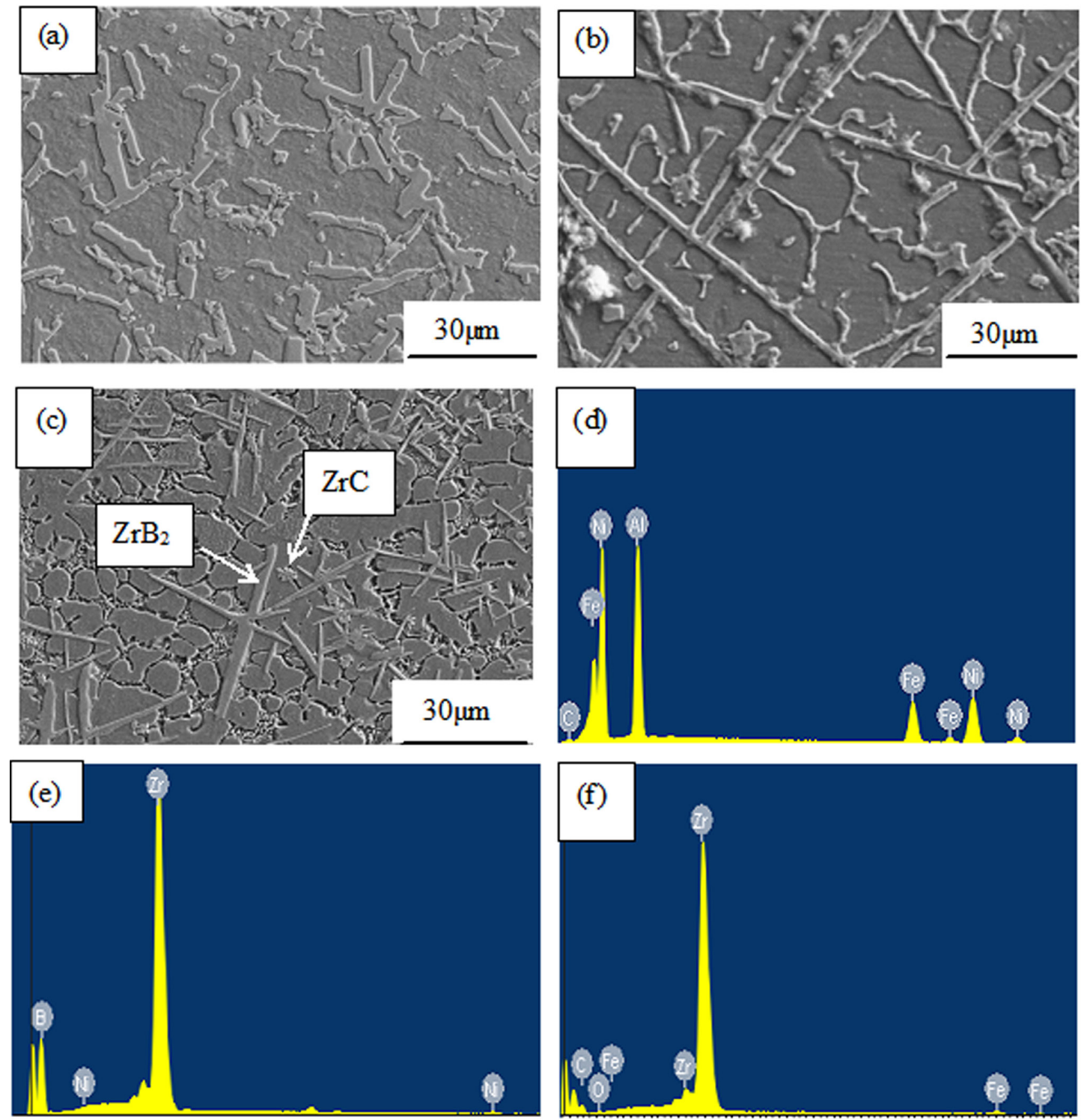

Figure 4. EPMA microstructure of the composite coatings (a) coating 1 (b) coating 2 (c) coating 3 (d) EDS of coating matrix (e) EDS of $\mathrm{ZrB}_{2}$ (f) EDS of $\mathrm{ZrC}$.

coating 1 and coating 2 with the cladding speed of $8 \mathrm{~mm} / \mathrm{s}$ and $9 \mathrm{~mm} / \mathrm{s}$. The element burn in the coating 3 is slight. The size of reinforcing phases of coating 3 is small (Figure 4). The fine $\mathrm{ZrC}$ and $\mathrm{ZrB}_{2}$ phases have better strengthening effect on the coating 3 . The hardness of coating 3 is higher.

Figure 8 shows the friction coefficient of coatings and Q235 steel in the course of tribological test. In the initial stage, the friction coefficient of coatings and Q235 substrate has a large change. Then the stable stage arises. The stable stage of Q235 steel occurs after 1400s during tribological test. The friction coefficient is about 0.66 . The friction coefficient of coating 1 is between 0.55 and 0.64 . The friction coefficient of coating 2 has the larger fluctuation as time goes. The friction coefficient is between 0.48 and 0.55 , which may be resulted from surface properties and other defects. The friction coefficient of coating 3 is between 0.42 and 0.45 , which is the minimum. The friction coefficients of coatings are lower than that of Q235. The strengthening phases are uniformly dispersed in the coatings, which has better strength to coatings. The indenter is difficult to penetrate deep into the coatings and can only reciprocate slightly on the surface of the coatings. The friction coefficient of coating is low. The oxide films are formed both on the NiAl matrix and reinforcing phases during tribological test ${ }^{20}$. They further act as protective layer. This is another reason that the friction coefficient of coating is lower than that of Q235 steel. The size of strengthening phases is the smallest (Figure 4c), which makes coating 3 has the highest hardness. The friction coefficient of the coating 3 is the lowest.

The wear volume of Q235 steel and coatings is shown in Figure 9 after tribological test for 3600s. It indicates that Q235 substrate has the largest wear volume $25.14 \times 109 \mu \mathrm{m}^{3}$. 

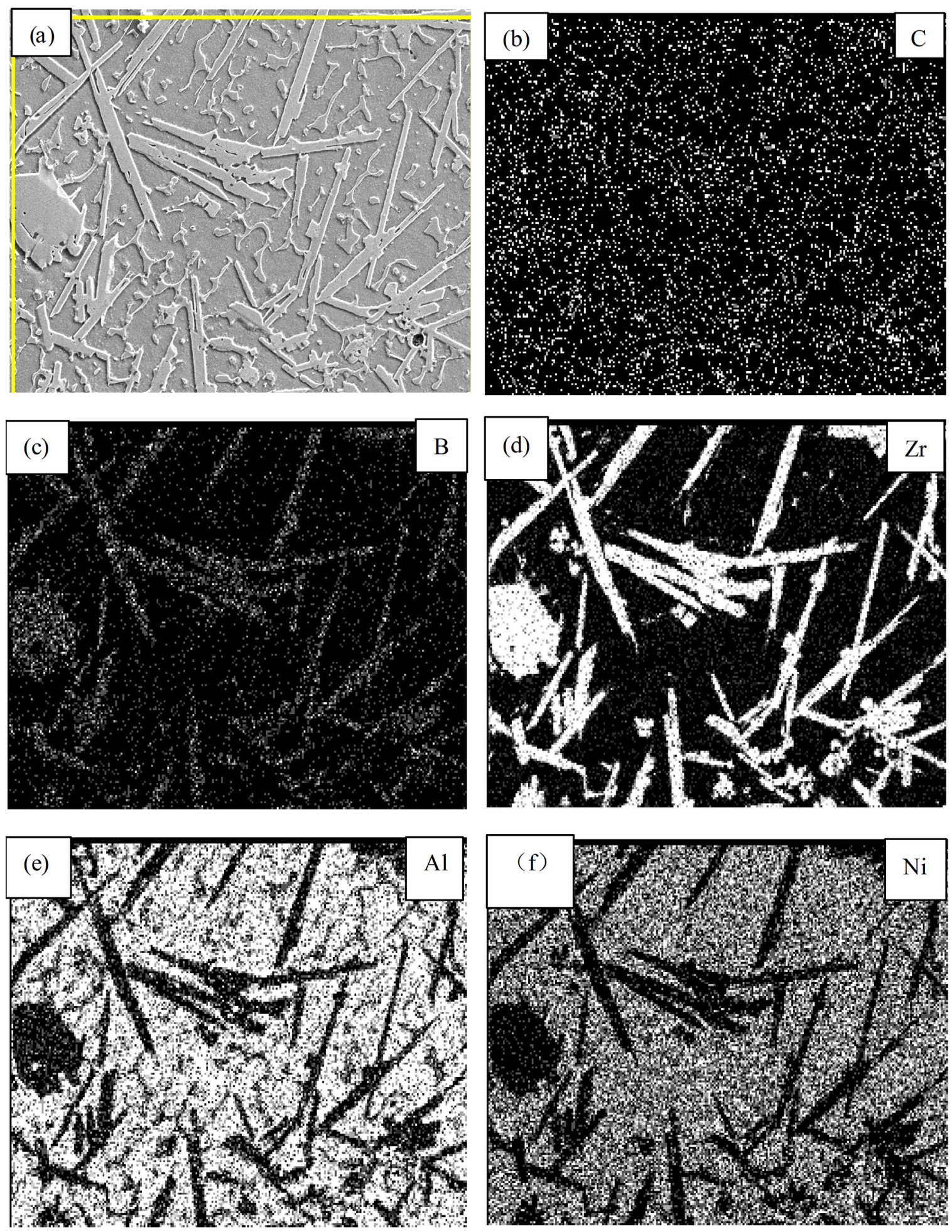

Figure 5. Surface scan map of coating 1 ( color and brightness represent the intensity of corresponding element).

The wear volume of coating 3 , coating 2 and coating 1 is $4.96 \times 10^{9} \mu \mathrm{m}^{3}, 9.73 \times 10^{9} \mu \mathrm{m}^{3}$ and $10.07 \times 10^{9} \mu \mathrm{m}^{3}$ respectively. The wear volume of coating 3 is the minimum. The experimental results show that the wear resistance of the coatings is superior to that of the substrate for the existence of strengthening phases.
The worn morphology of coatings and Q235 substrate are showed in Figure 10. Q235 has the characteristics of low hardness and good plasticity. The hardness of GCr15 steel ball as the friction pair is 63HRC, which is far harder than the Q235. Hence the steel ball is easy to penetrate into 

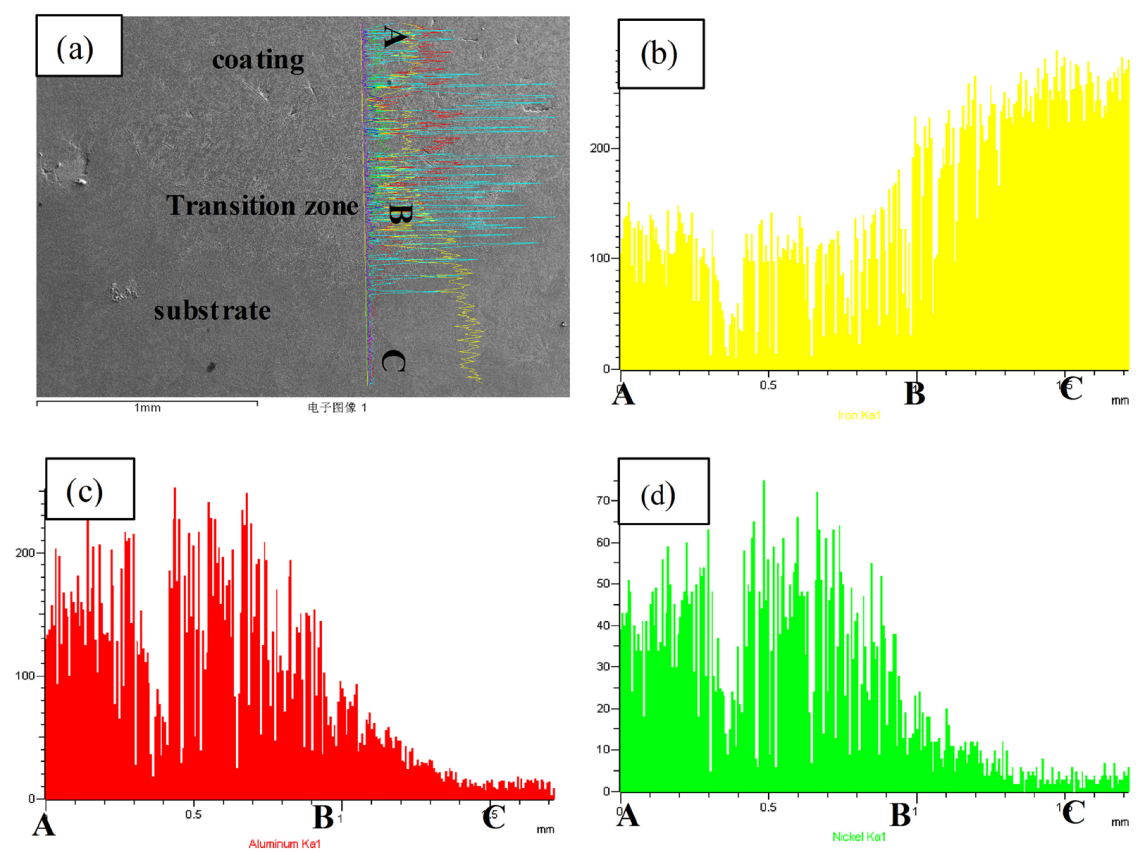

Figure 6. Line scanning of coating 3 (a) coating 3 and (b)(c)(d) element distribution.

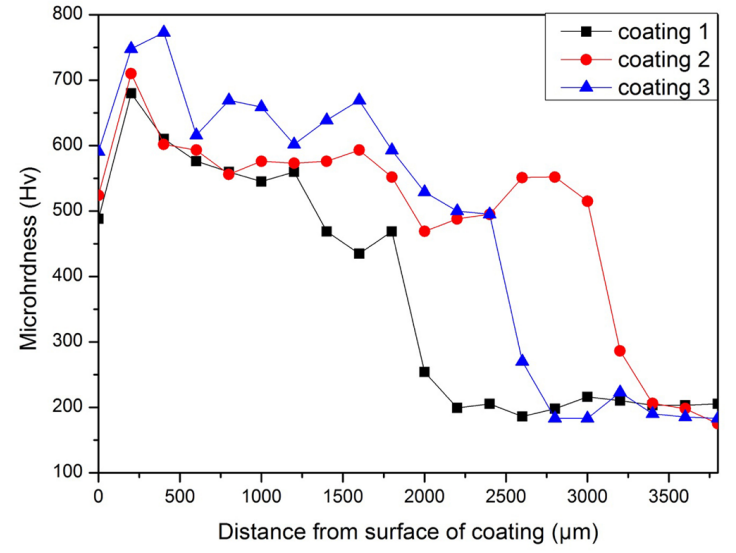

Figure 7. Microhardness curves of NiAl composite coatings.

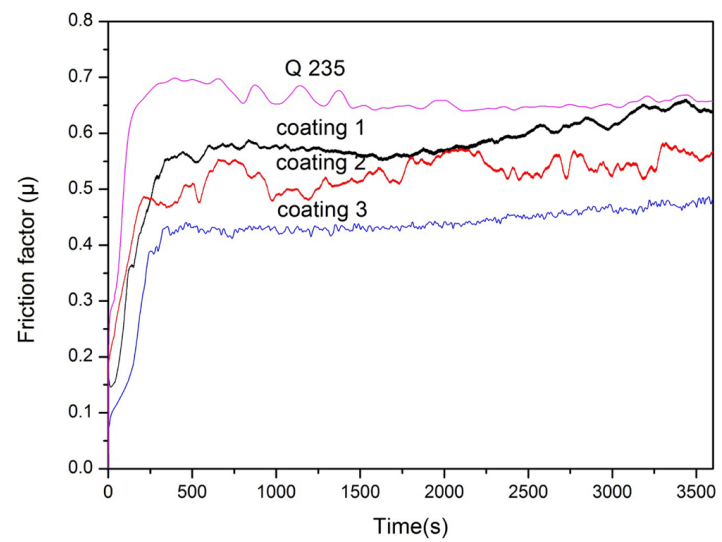

Figure 8. Variation curves of friction coefficient of coatings with the time. the surface of the Q235 for reciprocating cutting. When the prominent points of GCr15 ball have sharp edges and appropriate angle, it creates long and deep grooves (indicated by arrow in Figure 10b ). It is severe abrasive wear. When the prominent points of GCr15 ball have smooth edges. It can push some metal on the surface of the Q235 to the sides of the furrow and form a microscopic plough (Figure 10b). Since the abrasion process is repeated, the plow wrinkle will harden and fall off. It forms the worn debris. The worn debris detaches from the surface of Q235. Therefore, the adhesive wear is also a wear mechanism of Q235 substrate.

The worn morphology of coatings are different from that of Q235. The coatings hardness are far higher than that of Q235 substrate. The GCr5 ball can hardly penetrateinto the surface of the coatings. There are a few furrow and scratches (Figure 10d, f, h).

The size, volume fraction, distribution of the $\mathrm{ZrC}$ and $\mathrm{ZrB}_{2}$ particles have a great effect on the wear resistance of NiAl-based composite material. The reinforcing phases of high hardness can prevent the abrasive particles from being pressed into the surface of $\mathrm{NiAl}$ composite coatings during friction test. $\mathrm{ZrC}$ and $\mathrm{ZrB}$, reinforcements can take main load during sliding. Therefore, the worn surfaces are smooth and the grooves are narrow (Figure 10c, e, g). The main wear mechanism of NiAl-based coating with $\mathrm{ZrB}_{2}$ and $\mathrm{ZrC}$ reinforcing particles is adhesive. The reinforcement size of coating 3 is about $1-2 \mu \mathrm{m}$, which is smaller than that of coating 1. Coating 3 has high hardness. Coating 3 has higher wear resistance as compared with coatings 1 and 2 . There is slight scratch on the worn surface of coating 3 (Figure 10h).

The oxide film can improve the wear resistance of composite coating. The Ni, Al and Fe elements are oxidized and oxide films are formed on the surface of matrix during the tribological 


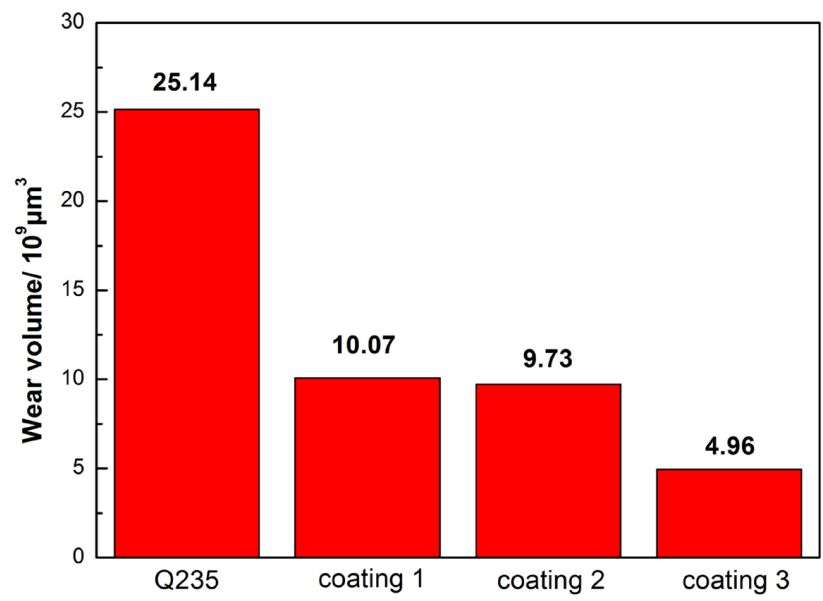

Figure 9. Wear volume of coatings.
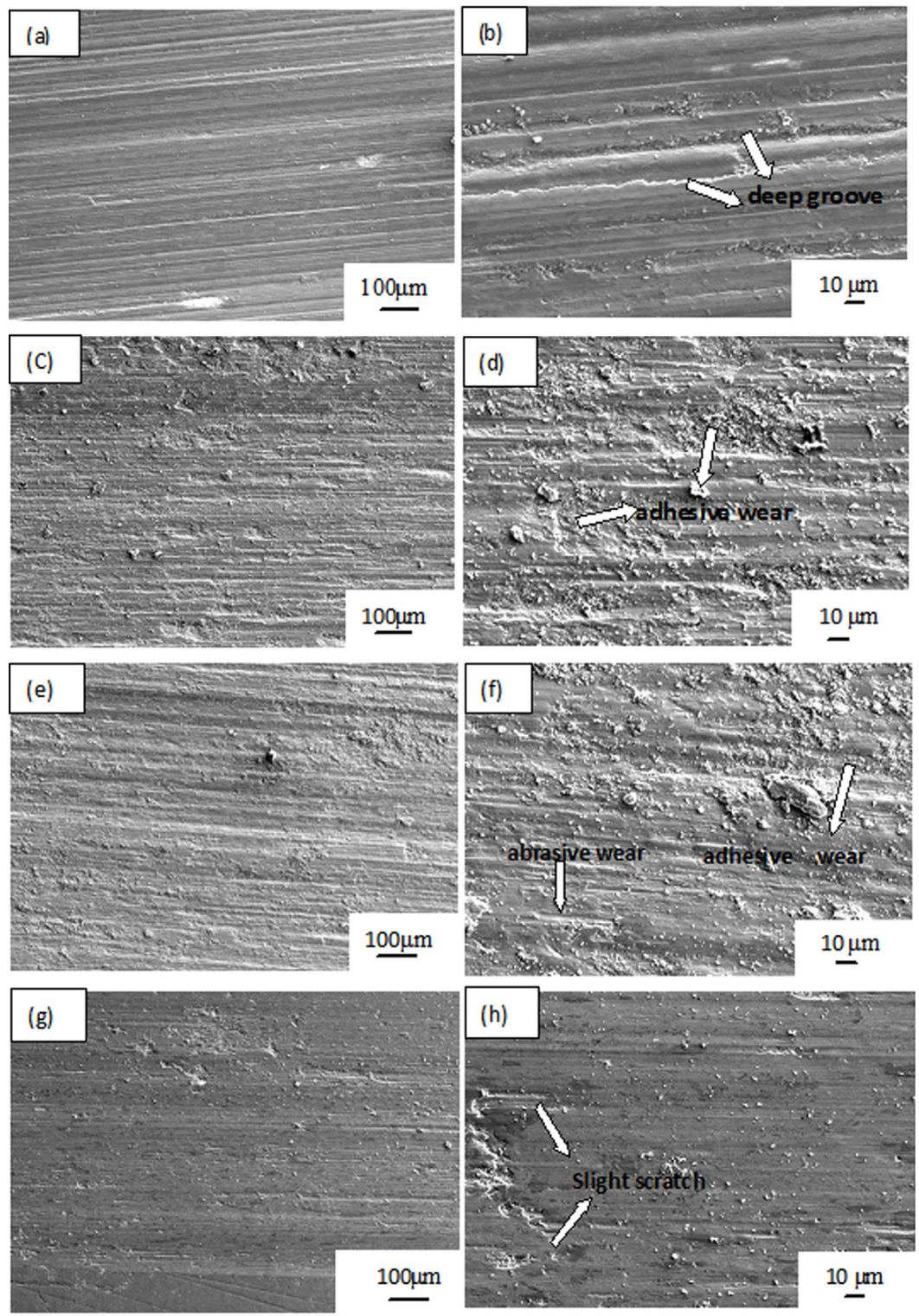

Figure 10. The worn morphology of Q235 and composite coatings (a)(b) Q235 substrate (c)(d) coating 1 (e)(f) coating 2 (g)(h) coating 3. 
test. The oxide films of $\mathrm{ZrC}$ and $\mathrm{ZrB}_{2}$ grains can also been formed on the surface of reinforcements. The oxide films act as a protective layer which prevents the adhesive interaction of mating surfaces ${ }^{20}$. It makes the composite coatings good wear resistance. The worn surface of composite coatings is smooth and has few and shallow furrows(Figure 10c, e, g).

\section{Conclusions}

(1) $\mathrm{ZrC}-\mathrm{ZrB}_{2} \mathrm{NiAl}$ composites coatings are prepared by plasma cladding technology with $\mathrm{Zr}, \mathrm{B}_{4} \mathrm{C}, \mathrm{Ni}$ and $\mathrm{Al}$ powders as raw materials. There are not any cracks and porosities in the coatings. The coatings have good metallurgical bonding with substrate.

(2) The microstructure of composite coatings is consist of $\mathrm{NiAl}, \boldsymbol{\gamma}-(\mathrm{Fe}, \mathrm{Ni}), \mathrm{ZrB}_{2}$ and $\mathrm{ZrC}$ phases. $\mathrm{ZrB}_{2}$ shows long needle bar shapes and $\mathrm{ZrC}$ shows small block shape. As the cladding speed increases, the size of the $\mathrm{ZrB}_{2}$ phase gradually becomes finer.

(3) The hardness and wear resistance of the coatings are much higher than the Q235 substrate. Coating 3 has the excellent properties because the strengthening phases are the finest and the surface is less burnt.

(4) The wear mechanism of Q235 is severe abrasive wear and severe adhesive wear. The wear mechanism of the NiAl-based coatings mainly is adhesive wear.

\section{Acknowledgments}

This research was supported by National KeyR\&DProgram of China (2018YFC0604703); the Natural Science Foundation of Shandong Province (ZR2018MEM008) and the National High Technology Research and Development Program of China (SS2015AA031901).

\section{References}

1. Kenneth H, Ali E. Influence of tribology on global energy consumption, costs and emissions. Friction. 2017;5(3):263-84.

2. Li B, Jia JH, Gao YM, Han MM, Wang WZ. Microstructural and tribological characterization of NiAl matrix self-lubricating composite coatings by atmospheric plasma spraying. Tribol Int. 2017;109:563-70

3. Poliarus O, Morgiel J, Umanskyi O, Pomorsk M, Bobrowski P, Szczerb MJ, et al. Microstructure and wear of thermal sprayed composite NiAl-based coatings. Arch Civ Mech Eng. 2019;19(4):1095-103.

4. Guan TG, Cao MQ, Xie K, Lv X, Tan YL. Microstructure and wear resistance of $\mathrm{ZrC}-\mathrm{ZrB}_{2} / \mathrm{Ni}$ composite coatings prepared by plasma transferred arc cladding. Mater Res. 2019;22(3):781-9.
5. Gong XY, Peng H, Ma Y, Guo HB, Gong SK. Microstructure evolution of an EB-PVD NiAl coating and its underlying single crystal superalloy substrate. J Alloys Compd. 2016;672:36-44.

6. Saeedi B, Sabour Rouh Aghdam A, Gholami G. A study on nanostructured in-situ oxide dispersed NiAl coating and its high temperature oxidation behavior. Surf Coat Tech. 2015;276:704-13.

7. Bochenek K, Basista M. Advances in processing of NiAl intermetallic alloys and composites for high temperature aerospace applications. Prog Aerosp Sci. 2015;79:136-46.

8. Cao LL, Cui HZ, Wu J, Tang HJ. Microstructures of ( $\mathrm{TiB}_{2}-$ $\mathrm{Al}_{2} \mathrm{O}_{3}$ )/NiAl composite prepared by in-situ reaction synthesis. Trans Nonferrous Met Soc China. 2012;22:2790-6.

9. Fang HC, Xiao P, Xiong X, Guang YU. Microstructures, mechanical and oxidation behaviors of $\mathrm{C} / \mathrm{C}$ composites modified by NiAl alloy. Trans Nonferrous Met Soc China. 2016;26:196202.

10. Adabi M, Amadeh AA. Formation mechanisms of Ni-Al intermetallics during heat treatment of $\mathrm{Ni}$ coating on $6061 \mathrm{Al}$ substrate. Trans Nonferrous Met Soc China. 2015;25:39-59.

11. Çamurlu H, Maglia F. Self-propagating high-temperature synthesis of $\mathrm{ZrB}_{2}$ or $\mathrm{TiB}_{2}$ reinforced $\mathrm{Ni}-\mathrm{Al}$ composite Powder. J Alloys Compd. 2009; 478:721-5.

12. Jayaseelan DD, Jackson H, Eakins E, Brown P, Lee WE. Laser modified microstructures in $\mathrm{ZrB}_{2}, \mathrm{ZrB}_{2} / \mathrm{SiC}$ and $\mathrm{ZrC}$. J Eur Ceram Soc. 2010;30:2279-88.

13. Xu J, Zou B, Zhao S, Yu H, Huang W, Xin Z, et al. Fabrication and properties of $\mathrm{ZrC}-\mathrm{ZrB}_{2} / \mathrm{Ni}$ cermet Coatings on amagnesium alloy by atmospheric plasma spraying of SHS powders. Ceram Int. 2014;40:15537-44.

14. $\mathrm{Ma} \mathrm{B}$, Li J. $\mathrm{ZrB}_{2}-\mathrm{SiC}-\mathrm{ZrC}$ coating on $\mathrm{ZrC}$ ceramics deposited by plasma spraying. Results in Physics. 2019;15:102550.

15. Zhang Y, Heng H, Zhang P, Hu Z, Li H, Zhang L. SiC/ZrB ${ }_{2}^{-}$ $\mathrm{SiC}-\mathrm{ZrC}$ multilayer coating for carbon/carbon composites against ablation. Surf Coat Tech. 2016;300:1-9.

16. Ning Z, Zhang N, Sheng G, Li S, Zhang G, Yue Z. Composition versus wear behaviour of air plasma sprayed $\mathrm{NiCr}-\mathrm{TiB}_{2}-\mathrm{ZrB}_{2}$ composite Coating. Coatings. 2018;8:273-87.

17. Lu L, Li H, Yin X, Lin H, Shen Q, Yao X, et al. Microstructure evolution of $\mathrm{SiC}-\mathrm{ZrB}$ - $\mathrm{ZrC}$ coating on $\mathrm{C} / \mathrm{C}$ composites at 1773 $\mathrm{K}$ under different oxygen partial pressures. J Alloys Compd. 2016;687:470-9.

18. Guan TG, Cao MQ, Xie K, Xia PC, Yue LJ, Lv X, et al. Effect of $\mathrm{SiC}$ addition on the microstructures and wear resistance of $\mathrm{ZrB}_{2}-\mathrm{ZrC}$ reinforced Ni-based composite coatings. Mater Res Express. 2019;6(9):050961.

19. Xia PC, Han GP, Xie K. Effect of compositions on the microstructure and properties of plasma clad NiAl coating. Met Mater Int. 2016;22:424-9.

20. Umanskyi O, Poliarus O, Ukrainets I, Martsenyuk I. Effect of $\mathrm{ZrB}_{2}, \mathrm{CrB}_{2}$ and $\mathrm{TiB}_{2}$ additives on the tribological characteristics of NiAl-based gas-thermal coatings. Key Eng Mater. 2014;604:20-3. 